\title{
The Relationship between Coronavirus Anxiety, Mindfulness and Spiritual Health in Patients with Cancer: A Survey in Southeast Iran
}

\author{
Mahlagha Dehghan', Zakieh Namjoo², Ahmad Zarei², Hanieh Tajedini², \\ Amir Bahrami², and Mohammad Ali Zakeri ${ }^{3,4} \bowtie$ \\ ${ }^{1}$ Nursing Research Center, Kerman University of Medical Sciences, Kerman, Iran \\ ${ }^{2}$ Student Research Committee, School of Nursing and Midwifery, Kerman University of Medical Sciences, Kerman, Iran \\ ${ }^{3}$ Non-Communicable Diseases Research Center, Rafsanjan University of Medical Sciences, Rafsanjan, Iran \\ ${ }^{4}$ Social Determinants of Health Research Centre, Rafsanjan University of Medical Sciences, Rafsanjan, Iran
}

Objective The sudden outbreak of COVID-19 has caused major health problems, including anxiety in cancer patients worldwide. Spiritual health and mindfulness are considered as factors affecting anxiety. This study addressed the relationship between COVID-19 anxiety, spiritual health and mindfulness in patients with cancer.

Methods One hundred and eighty-four cancer patients participated in this cross-sectional study. The data were collected with convenience sampling method from two oncology centers from 15 June to 15 July 2020 in the southeast Iran. Patients completed the Demographic and Clinical Characteristics Form, Corona Disease Anxiety Scale (CDAS), The Freiburg Mindfulness inventory-Short Form (FMI-SF) and Spiritual Health Scale.

Results According to the psychological symptom subscale (CDAS), $61.4 \%$ of the participants had moderate to severe anxiety. According to the physical symptom subscale, $38 \%$ of the participants had moderate to severe anxiety. No significant association was found between corona disease anxiety and mindfulness/spiritual health $(\mathrm{p}>0.05)$.

Conclusion The results of this study showed high levels of mental and physical anxiety and worries about COVID-19 disease in cancer patients, which led to challenges in their lives. It is necessary to review and implement effective interventions in future studies to prevent anxiety and its consequences in cancer patients.

Psychiatry Investig 2021;18(5):443-452

Key Words COVID-19, Cancer, Anxiety, Mindfulness, Spiritual health.

\section{INTRODUCTION}

The sudden outbreak of pneumonia in China in late 2019 led to the identification of a new virus called 2019-nCoV (COVID-19), which quickly became a health problem in the world. The high contagiousness of the virus prompted the World Health Organization (WHO) to declare a pandemic condition in the world. ${ }^{1}$ The latest meta-analysis of 50,466 infected patients showed the mortality rate of $4.3 \%$. However, most of those who

Received: December 22, 2020 Revised: February 9, 2021 Accepted: February 20, 2021

$\triangle$ Correspondence: Mohammad Ali Zakeri, MSc

Non-Communicable Diseases Research Center, Rafsanjan University of Medical Sciences, Health Center No. 4, Western Amir Kabir Avenue, Rafsanjan, Kerman province, Iran

Tel: +98 34 34323481, E-mail: ma.zakeri115@gmail.com

(c) This is an Open Access article distributed under the terms of the Creative Commons Attribution Non-Commercial License (https://creativecommons.org/licenses/bync/4.0) which permits unrestricted non-commercial use, distribution, and reproduction in any medium, provided the original work is properly cited. died had previous chronic and underlying diseases with weakened immune systems. ${ }^{2}$ Studies have shown that cancer is a risk factor for severe complications and the course of the disease in patients with COVID-19. ${ }^{3}$ Cancer has become a major health problem worldwide, ranking the second in the US. ${ }^{4}$ According to studies, more than 16.9 million Americans had cancer until January 1, 2019, and it is predicted that more than 22.1 million people will have suffered from cancer by January 1,2030 because of the growth of aging in communities. ${ }^{5}$

Cancer patients are exposed to many traumas and problems caused by other diseases due to the problems associated with this disease and systemic immunosuppressive state because of malignancy and treatments such as chemotherapy or surgery. The risk of acute conditions in cancer patients is significantly higher than that in the general population. Therefore, cancer patients may be at higher risk for COVID-19 with a poorer prognosis. ${ }^{6.7}$ The prevalence of COVID-19 infection in 
cancer patients has been reported to be up to $7.8 \%$, which despite cancer, increases the susceptibility to COVID-19 infection in individuals. ${ }^{8}$

In the COVID-19 epidemic, cancer patients are at greater risk for health-related quality of life (HRQoL) problems, anxiety, and mental and physical stress. ${ }^{9}$ COVID- 19 anxiety can influence cancer patients' decision on seeking and continuing treatment. Cancer patients face many challenges and anxious situations in the prevalence of COVID-19 disease, which lead to non-referral to hospitals and follow-up treatment, ${ }^{10}$ and the possibility of canceling appointments at the oncology/hematology clinic. ${ }^{11}$ Anxiety about COVID-19 is common and seems to be due to the unknown and confusing nature of the virus. Fear of the unknown reduces the perception of immunity in humans and has always been stressful for them. Studies have reported high levels of anxiety and stress in the prevalence of COVID-19 disease. ${ }^{12,13}$ Anxiety is defined as a feeling of worry, anger, or dissatisfaction with something with an uncertain outcome. ${ }^{14}$ High, persistent, and long-term anxiety and stress can lead to maladaptation, and if the stresses experienced are not properly managed, they will have a great impact on individuals' health. ${ }^{15}$

Mindfulness-based therapy is a method through which the patient becomes aware of negative emotions such as anxiety and stress. ${ }^{16}$ Mindfulness is a balanced mental framework and a concept related to awareness and consciousness, which prevents emotional and unfortunate magnifications and provides an opportunity to distance oneself from unpleasant emotional states such as various pressures and stresses. ${ }^{17}$ Various studies have shown that mindfulness can reduce stress and anxiety of the cancer patients. ${ }^{18-22}$ Mindfulness can affect the quality of life of cancer patients directly and indirectly. ${ }^{23}$ Mindfulness plays a vital role in explaining the important components of mental health in cancer patients. Mehdi Pour and $\mathrm{Kord}^{24}$ have shown that mindful people evaluate life-threatening situations with less anxiety and stress and adapt to stressful situations more. Tate et al..$^{25}$ showed that mindfulness created a new and alternative perspective on how patients can change their perceptions of themselves and the world around them. Hsieh et al. ${ }^{26}$ showed that mindfulness was significantly associated with stress and depressive symptoms in the caregivers of the lung cancer patients. Zhong et al. ${ }^{27}$ also indicated that mindfulness was negatively associated with perceived stress, anxiety and depression, and loss of self-confidence in Chinese patients with gastrointestinal cancer.

Spirituality is a factor that may be effective in coping with stress and anxiety related to the COVID-19. Spirituality is one of the human capabilities that provides problem-solving and coping strategies. In addition, spirituality, as a source of social support creates a meaningful sense for coping with confusion and natural disasters, and increases the sense of indirect control over events. ${ }^{28}$ Many physicians today consider faith and spirituality an important source in physical health, so that it is necessary to pay attention to patients' spiritual issues in the course of treatment. ${ }^{29}$ Spiritual health can be defined as a sense of communication with others, perception of meaning and goals, and association with a superior power that helps people live better and interact more effectively with the world around them. Spiritual health is created when people voluntarily strengthen their spiritual power through prayer, relaxation, and association with like-minded people, learning from a spiritual guide and reading. ${ }^{30}$

A review of the literature shows that most studies have focused on variables related to COVID-19 anxiety in the general population or medical team ${ }^{31,32}$ and few studies in particular have focused on the factors associated with the COVID-19 anxiety in cancer patients. ${ }^{33}$ Regarding the importance of spiritual health and mindfulness in promoting adaptation to chronic diseases and the limited number of studies in this regard, this study aimed to investigate the relationship between COVID-19 anxiety, mindfulness and spiritual health in cancer patients in southeastern Iran.

\section{METHODS}

\section{Study design and setting}

This was a cross-sectional and descriptive-analytical study. The research settings were two oncology centers (Bahonar Hospital and Javad Alaemeh Clinic) affiliated to Kerman University of Medical Sciences. Javad-Alaemeh Clinic with 25 beds and Bahonar Hospital with 45 beds admitted patients in three shifts (morning, evening $\&$ night). These centers are the crowded ones in the southeast Iran.

\section{Sample size and sampling}

The study population consisted of male and female patients with cancer referred to the research setting. Patients with the inclusion criteria were considered eligible to participate in the study.

Inclusion criteria: 1) patients aged over 18 years (to have a correct understanding of the questions), 2) patients diognosed with cancer. Exclusion criteria: 1) patient's psychological and physiological instability during sampling, 2) failure to complete more than $10 \%$ of each of the questionnaires.

A pilot study on 30 eligible participants and the following formula were used to estimate the sample size.

$$
n=\left(\frac{z_{1-\frac{\alpha}{2}}+z_{1-\beta}}{0.5 \ln \left(\frac{1+r}{1-r}\right)}\right)^{2}+3
$$


The type I and type II errors were considered $0.05 \%$ and $20 \%$, respectevely. The correlation coefficient between COVID anxiety and mindfulness of the patients with cancer in the pilot study was 0.227 . According to the aforementioned indicators, 151 samples were included in this study. Concerning the probability of dropouts, 225 questionnaires were provided to the samples with inclusion criteria, of which 184 questionnaires were completed. Therefore, the response rate was $81.77 \%$. Furthermore, out of 184 completed questionnaires, there was less than 0.01 missing value. Therefore, 184 questionnaires were statistically analyzed. It is noteworthy that the pilot study was considered in the total sample. Convenience sampling method was used.

\section{Measures}

\section{Demographic and Clinical Charectristices Form}

This form included age, sex, marital status, educational level, occupation, monthly income, living place, living with family, duration of diognosis with cancer, type of cancer, type of treatment, being aware of cancer, history of addiction, other chronic diseases, infection with COVID-19 (his/herself, family member, firend or reletive), and the effect of COVID-19 related conditions on the course of cancer treatment.

\section{Corona Disease Anxiety Scale (CDAS)}

The CDAS was developed by Alipour et al. ${ }^{34}$ in 2020 to mesure corona disease related anxiety in Iranina population. This scale consists of 18 items and two subscales of psychological ( 9 items) and physical symptoms ( 9 items) in a 4-point Likert scale format $(0=$ never, $1=$ sometimes, $2=$ often, and $3=$ always $)$. The minimum score of this scale is 0 and the maximum score is 54 , with higher score indicating higher level of anxiety. In addition, the scores between 0-16 indicate no/mild anxiety, 17-29 refelect moderate anxiety and 30-54 indicate sever anxiety. In the psychological symptom subscale, the scores between 0-5 indicate no/mild anxiety, 6-19 refelect moderate anxiety and 20-27 indicate sever anxiety. In the physical symptom subscale, the scores between $0-1$ indicate no/mild anxiety, $2-9$ refelect moderate anxiety and 10-27 indicate sever anxiety.

The CDAS shows a good internal consistency. Its Cronbach's alpha was reported to be 0.91 for samples aged $18-60$ years old. The CDAS has a convergent validity with General Health Quessionare-28 [GHQ-280 ( $\mathrm{r}=0.48, \mathrm{p}=0.01)$ ]. In addition, The CDAS has goodness of fit index according to confirmatory factor analysis. ${ }^{34}$ In the present study, the Cronbach's alpha of CDAS was 0.87 .

The Freiburg Mindfulness inventory-Short Form (FMI-SF)

Buchheld et al. ${ }^{35,36}$ designed the initial Freiburg Mindfulness
Inventory, which consisted of 30 items. The initial form of this inventory includes 4 factors such as mindful presence, nonjudgmental acceptance, openness to experience and insight. ${ }^{35}$ Later, Walach et al..$^{35}$ designed the short form (14 items) of this inventory, which is more suitable for the general population and for groups that are not very familiar with the Buddhist root of mindfulness and it can be used in different cultures. Kohls et al. ${ }^{37}$ showed that the short form measured the two factors of presence and acceptance. The items are based on a 4-point Likert scale ( (rarely $=1$ to almost always $=4$ ). It should be noted that the phrase number 13 is scored reversely. The minimum score in this questionnaire is 14 and the maximum is 56 , with higher score reflecting higher mindfulness. ${ }^{35}$

Ghasemi Jobaneh et al. ${ }^{38}$ showed acceptable and sufficient reliability of the short form of the Freiburg Mindfulness Inventory (FMI-SF). The reliability coefficient of the whole scale was 0.83 indicating the good retest reliability of the inventory. In the present study, the Cronbach's alpha of FMI-SF was 0.84 .

\section{Spiritual health scale}

The spiritual health scale of Palutzian \& Ellison (1928) was used to measure the spiritual health, which consists of 20 items with two subscales of religious health (ten items) and existential health (ten items). The items were about how much participants engage in spiritual health with a 6-point Likert scale, ranging from 1 (strongly disagree) to 6 (strongly agree). The score for the spiritual health was the sum of the two subscales ranging from 20 to 120 . The scores of 20-40, 41-99, and 100120 show low, moderate, and high spiritual health, respectively. Its validity and reliability have been confirmed (Alpha coefficient $=0.82$ ). ${ }^{39}$ In the present study, the Cronbach's alpha of the spiritual health scale was 0.81 .

\section{Data collection procedure and statistical analysis}

The researchers referred to the centers after obtaining a code of ethics from the ethics committee. After selecting the eligible patients, clarifying the purpose of the study, and obtaining written consent from the patients, the patients completed the questionnaire when they were in a good physical condition. For those patients who were unaware of their diseases or uneducated, a researcher asked the questions orally and filled the questionnaire. The interviewers were nursing students and had no conflict of interest (i.e. they did not know any patients and they were not passing any courses in oncology centers when interviewing the participants). The data were collected during one month (from 15 June to 15 July 2020).

SPSS 25 (IBM Corp., Armonk, NY, USA) was used for data analysis. Frequency, percentage, mean and standard deviation were used to describe the sample characteristics, the CDAS, mindfulness and spiritual health scores. Spearman's rho corre- 
lation coefficient was used to check the correlations between CDAS, mindfulness and spiritual health scores. Mann-Whitney $\mathrm{U}$ and Kruskal-Wallis $\mathrm{H}$ tests were used to check the association between qualitative variables and CDAS score. Significance level was considered 0.05 .

\section{Ethical considerations}

The code of ethics (IR.KMU.REC.1399.182) was received from the Ethics Committee of Kerman University of Medical Sciences. In this project, the purpose of the research was fully explained to the participants who could withdraw from the study at any time. They were explained that participating in or withdrawing from the study would not affect their course of treatment, and all their information would remain confidential.

\section{RESULTS}

The mean age of the study participants was $52.85 \pm 14.66$ years $(\min =20$ and $\max =80)$. The majority of the samples were female, married, educated, and unemployed. The monthly income level of most of the samples was $<2$ million Tomans a month (25,000 Tomans=one Dollar). The majority of the participants were insured and living with their family (Table 1). The clinical characteristics of the participants are presented in Table 2. Only one patient was infected with COVID-19 and only $1.6 \%(n=3)$ of the family members of patients with cancer were infected with COVID-19.7.6\% $(n=14)$ of the friends or relatives of patients were infected with COVID-19. 26.1\% $(n=48)$ of the patients believed that COVID-19 outbreak and lockdown influenced their course of cancer treatment.

Table 1. Demographic characteristics of the participants and COVID-19 anxiety differences among the participants

\begin{tabular}{|c|c|c|c|c|c|c|}
\hline \multirow{2}{*}{ Variable } & \multirow{2}{*}{ Frequency (\%) } & \multicolumn{3}{|c|}{ COVID-19 anxiety } & \multirow{2}{*}{ Statistical test } & \multirow{2}{*}{$\mathrm{p}$ value } \\
\hline & & Mean & SD & Median & & \\
\hline Sex & & & & & $Z=-0.26$ & 0.80 \\
\hline Female & $106(57.6)$ & 12.29 & 11.51 & 9 & & \\
\hline Male & $78(42.4)$ & 11.95 & 11.55 & 8 & & \\
\hline Marital status & & & & & $\mathrm{H}=3.73$ & 0.16 \\
\hline Single & $15(8.2)$ & 8.53 & 9.62 & 4 & & \\
\hline Married & $152(82.6)$ & 12.75 & 11.74 & 9 & & \\
\hline Divorced/widow(er) & $17(9.2)$ & 9.94 & 10.43 & 8 & & \\
\hline Education level & & & & & $\mathrm{H}=4.22$ & 0.24 \\
\hline Uneducated & $41(22.3)$ & 11.61 & 14.02 & 5 & & \\
\hline Middle/high school & $57(31.0)$ & 11.79 & 10.56 & 9 & & \\
\hline Diploma & $45(24.5)$ & 13.62 & 11.63 & 10 & & \\
\hline Academic & $41(22.3)$ & 11.56 & 9.99 & 9 & & \\
\hline Occupation & & & & & $Z=-2.21$ & 0.027 \\
\hline Employed & $60(32.6)$ & 14.85 & 12.66 & 11 & & \\
\hline Unemployed & $124(67.4)$ & 10.84 & 10.70 & 8 & & \\
\hline Income (Million Tomans) & & & & & $\mathrm{H}=7.55$ & 0.023 \\
\hline$<1$ & $59(32.1)$ & 11.41 & 12.49 & 7 & & \\
\hline $1-2$ & $54(29.3)$ & 15.39 & 11.91 & 12 & & \\
\hline$>2$ & $71(38.6)$ & 10.30 & 9.88 & 8 & & \\
\hline Living place & & & & & $\mathrm{H}=4.40$ & 0.22 \\
\hline Kerman city & $96(52.2)$ & 11.09 & 10.24 & 8 & & \\
\hline Kerman villages & $17(9.2)$ & 8.35 & 9.75 & 6 & & \\
\hline Other cities in Kerman province & $61(33.2)$ & 14.16 & 12.48 & 11 & & \\
\hline Other provinces & $10(5.4)$ & 16.40 & 16.88 & 13 & & \\
\hline Living with family & & & & & $Z=-0.34$ & 0.74 \\
\hline Yes & $177(96.2)$ & 12.06 & 11.45 & 8 & & \\
\hline No & $7(3.8)$ & 14.28 & 13.47 & 9 & & \\
\hline
\end{tabular}

SD: standard deviation, H: Kruskal-Wallis H, Z: Mann-Whitney U 
The mean score of CDAS was $12.15 \pm 11.50(\min =0, \max =$ 50). Eighteen participants (9.8\%) had severe anxiety, 34 (18.5\%) had moderate anxiety and $132(71.7 \%)$ had no/mild anxiety. The mean score of CDAS-psychological symptom subscale was $9.44 \pm 8.05$ ( $\min =0, \max =27)$. Thirty-one $(16.8 \%)$ had severe anxiety, 82 (44.6\%) had moderate anxiety and 71 (38.6\%) had no/mild anxiety. The mean score of CDAS-physical symptom subscale was $2.71 \pm 4.56(\mathrm{~min}=0, \max =23)$. Nineteen participants (10.3\%) had severe anxiety, $51(27.7 \%)$ had moderate anxiety and 114 (62\%) had no/mild anxiety.

Among the CDAS-psychological symptom subscale items, $59.3 \%$ of the participants often/always were concerned about the transmission of coronavirus to others and $40.2 \%$ were extremely worried about the spread of corona disease. Among the CDAS-physical symptom subscale items, $19.5 \%$ of the participants often/always reduced their physical activities because of fear of coronavirus and the corona disease has become a nightmare in $13.1 \%$ of them (Table 3 ).

The mean score of mindfulness was $40.52 \pm 7.84$, which was greater than the midpoint of the questionnaire i.e. 35 . The mean score of spiritual health was $91.58 \pm 14.01$ (Table 4 ). Fifty-one $(27.7 \%)$ of the participants had high level of spiritual health, $132(71.7 \%)$ had moderate level of spiritual health and only one patient had poor spiritual health.

Table 2. Clinical characteristics of the participants and COVID-19 anxiety differences among the participants

\begin{tabular}{|c|c|c|c|c|c|c|}
\hline \multirow{2}{*}{ Variable } & \multirow{2}{*}{ Frequency (\%) } & \multicolumn{3}{|c|}{ COVID-19 anxiety } & \multirow{2}{*}{ Statistical test } & \multirow{2}{*}{$\mathrm{p}$ value } \\
\hline & & Mean & $\mathrm{SD}$ & Median & & \\
\hline Duration of diagnosis with cancer (months) & & & & & $\mathrm{H}=0.52$ & 0.92 \\
\hline$\leq 6$ & $78(42.4)$ & 12.44 & 11.42 & 10 & & \\
\hline $7-12$ & $52(28.3)$ & 11.19 & 11.26 & 7 & & \\
\hline $13-24$ & $37(20.1)$ & 11.40 & 9.48 & 9 & & \\
\hline$>24$ & $17(9.2)$ & 15.35 & 16.19 & 10 & & \\
\hline Type of cancer & & & & & $\mathrm{H}=9.37$ & 0.15 \\
\hline Breast & $52(28.3)$ & 10.17 & 11.16 & 6.5 & & \\
\hline Gastrointestinal & $47(25.5)$ & 14.26 & 11.33 & 12 & & \\
\hline Respiratory & $27(14.7)$ & 9.07 & 9.31 & 6 & & \\
\hline Lymphoma & $14(7.6)$ & 15.07 & 14.26 & 12.5 & & \\
\hline Bone marrow & $9(4.9)$ & 9.33 & 10.95 & 6 & & \\
\hline Genitalia & $18(9.8)$ & 14.94 & 14.03 & 11 & & \\
\hline Other & $17(9.2)$ & 13.35 & 10.31 & 11 & & \\
\hline Cancer treatment & & & & & $\mathrm{H}=3.95$ & 0.27 \\
\hline Chemotherapy & $75(40.8)$ & 12.91 & 11.14 & 11 & & \\
\hline Chemotherapy/surgery & $64(34.8)$ & 10.48 & 10.67 & 7 & & \\
\hline Chemotherapy/radiotherapy/surgery & $32(17.4)$ & 14.56 & 13.78 & 9 & & \\
\hline Other & $13(7.0)$ & 10.0 & 11.07 & 5.0 & & \\
\hline Being aware of cancer & & & & & $Z=-0.56$ & 0.57 \\
\hline Yes & $147(79.9)$ & 12.23 & 11.41 & 8 & & \\
\hline No & $37(20.1)$ & 11.81 & 12.0 & 9 & & \\
\hline History of addiction & & & & & $Z=-0.61$ & 0.54 \\
\hline Yes & $44(23.9)$ & 12.57 & 13.55 & 6.5 & & \\
\hline No & $140(76.1)$ & 12.01 & 10.82 & 9 & & \\
\hline History of chronic disease & & & & & $Z=-0.24$ & 0.81 \\
\hline Yes & $146(79.3)$ & 12.21 & 11.43 & 9 & & \\
\hline No & $38(20.7)$ & 11.89 & 11.88 & 8 & & \\
\hline Effect of COVID on treatment & & & & & $Z=-1.66$ & 0.10 \\
\hline Yes & $48(26.1)$ & 14.6 & 12.21 & 11 & & \\
\hline No & $136(73.9)$ & 11.28 & 11.15 & 8 & & \\
\hline
\end{tabular}

SD: standard deviation, H: Kruskal-Wallis H, Z: Mann-Whitney U 
No significant correlation was found between CDAS, mindfulness and spiritual health. There was a significant correlation between mindfulness and spiritual health (Table 4).

No significant correlation was found between CDAS and age $(\mathrm{r}=-0.12, \mathrm{p}=0.12)$. CDAS score of the employed patients was significantly greater than that of unemployed patients $(\mathrm{p}=0.027)$. CDAS score of the patients with less than 2-million-Toman income was significantly greater than that of those with higher income ( $\mathrm{p}=0.023$ ). CDAS score was not different among other qualitative variables (Tables 1 and 2).

\section{DISCUSSION}

In the unfavorable conditions of the COVID-19, it is crucial to study the negative factors related to this disease and reduces the long-term psychological burden. ${ }^{40}$ This study aimed to determine the relationship between the COVID-19 anxiety, mindfulness and spiritual health in cancer patients. In the present study, more than a quarter of the participants had moder- ate/severe anxiety and $26.1 \%$ of them believed that the prevalence of COVID-19, its barriers and conditions affected the course of treatment. Chen et al. ${ }^{33}$ also showed a high prevalence of fear of disease progression, anxiety and depression in cancer patients during the outbreak of COVID-19. Use of SelfRating Anxiety Scale (SAS) in respiratory cancer patients showed a positive association between anxiety level, delayed treatment, discontinuation of treatment, deep concern about COVID-19, and diagnosis of respiratory cancer. Liang et al. ${ }^{3}$ showed that COVID-19 anxiety could influence cancer patients' decision on seeking and continuing treatment. Lives of cancer patients have been affected by the onset of COVID-19 and a variety of challenges. Due to the critical condition of COVID-19 disease, cancer patients have to spend more time at home and less time in the community. Cancer patients' communication with the community and their health care professionals, who convey accurate information about the disease has decreased. ${ }^{41}$ The current state of the COVID-19 epidemic has also made it difficult for doctors to make decisions. The daily routine of can-

Table 3. The participants' responses to Corona Disease Anxiety Scale

\begin{tabular}{|c|c|c|c|c|}
\hline \multirow{2}{*}{ Items } & \multicolumn{4}{|c|}{ Responses (N/\%) } \\
\hline & Never & Sometimes & Often & Always \\
\hline 1. Thinking about coronavirus makes me anxious. & $88(47.8)$ & $42(22.8)$ & $13(7.1)$ & $41(22.3)$ \\
\hline 2. I feel tense when I am thinking about the corona threat. & $99(53.8)$ & $37(20.1)$ & $11(6.0)$ & $37(20.1)$ \\
\hline 3. I am extremely worried about the spread of corona disease. & $68(37.0)$ & $42(22.8)$ & $19(10.3)$ & $55(29.9)$ \\
\hline 4. I am afraid of being infected with coronavirus. & $84(45.7)$ & $42(22.8)$ & $18(9.8)$ & $40(21.7)$ \\
\hline 5. I think I may get coronavirus at any moment. & $107(58.2)$ & $38(20.6)$ & $11(6.0)$ & $28(15.2)$ \\
\hline 6. I think I have gotten the corona with every single sign and check myself. & $121(65.8)$ & $27(14.7)$ & $11(6.0)$ & $25(13.5)$ \\
\hline 7. I am worried about the transmission of the coronavirus to people around me. & $44(23.9)$ & $31(16.8)$ & $32(17.5)$ & $77(41.8)$ \\
\hline 8. Corona anxiety has disrupted my activities. & $105(57.0)$ & $29(15.8)$ & $18(9.8)$ & $32(17.4)$ \\
\hline 9. The media attention to corona worries me. & $94(51.1)$ & $39(21.2)$ & $14(7.6)$ & $37(20.1)$ \\
\hline 10. Thinking about corona has disturbed my sleep. & $157(85.3)$ & $18(9.8)$ & $5(2.7)$ & $4(2.2)$ \\
\hline 11. Thinking about corona has made me lose my appetite. & $168(91.3)$ & $8(4.3)$ & $2(1.1)$ & $6(3.3)$ \\
\hline 12. I get headache when I am thinking about corona. & $160(87.0)$ & $15(8.1)$ & $4(2.2)$ & $5(2.7)$ \\
\hline 13. My body trembles when I am thinking about corona. & $157(85.3)$ & $16(8.7)$ & $5(2.7)$ & $6(3.3)$ \\
\hline 14. When I am thinking about corona, I get goose bumps. & $163(88.6)$ & $9(4.9)$ & $7(3.8)$ & $5(2.7)$ \\
\hline 15. Corona has become a nightmare for me. & $146(79.3)$ & $14(7.6)$ & $11(6.0)$ & $13(7.1)$ \\
\hline 16. My physical activity has decreased due to the fear of corona. & $126(68.5)$ & $22(12.0)$ & $17(9.2)$ & $19(10.3)$ \\
\hline 17. It is difficult for me to talk about corona with others. & $148(80.3)$ & $15(8.2)$ & $6(3.3)$ & $15(8.2)$ \\
\hline 18. I get a heartbeat when I am thinking about corona. & 158 (85.9) & $12(6.5)$ & $6(3.3)$ & $8(4.3)$ \\
\hline
\end{tabular}

Table 4. The correlation between COVID-19 related anxiety, mindfulness, and spiritual health among patients with cancer

\begin{tabular}{lccccccc}
\hline \multirow{2}{*}{ Variable } & Mean & $\begin{array}{c}\text { Standard } \\
\text { deviation }\end{array}$ & Minimum & Maximum & \multicolumn{3}{c}{ Spearman's rho correlation coefficient } \\
\cline { 6 - 8 } & & & & COVID-19 anxiety & Mindfulness & Spiritual health \\
\hline COVID-19 anxiety & 12.15 & 11.50 & 0 & 50 & 1 & & \\
Mindfulness & 40.52 & 7.84 & 17 & 56 & $0.09(\mathrm{p}=0.23)$ & 1 & 1 \\
Spiritual health & 91.58 & 14.01 & 35 & 120 & $0.12(\mathrm{p}=0.11)$ & $0.47(\mathrm{p}<0.001)$ & 1 \\
\hline
\end{tabular}


cer specialists in caring for cancer patients has changed, without strong evidence and recommendations. ${ }^{42}$ This condition causes more anxiety in cancer patients.

Health care resources were mobilized to fight coronavirus infection. Cancer patients, their caregivers, and health care professionals do not know whether to continue treatment or wait for the COVID-19 pandemic to go away. ${ }^{43}$ Büntzel et al. ${ }^{44}$ also showed that nearly half of the participants ( $43 \%$ of patients and $47 \%$ of physicians) expected negative consequences for patients' physical condition, and that cancer patients felt emotional stress in $34 \%$ of their physicians. Cancer patients are concerned about COVID-19 and its effects.

The results of the present study showed that more than half of the cancer patients (59.3\%) were concerned about the spread of COVID-19 disease in people around them and $40.2 \%$ of the participants were extremely concerned about the prevalence of the coronavirus infection. Coronavirus has become a nightmare in $13.1 \%$ of the participants. In addition to the problems caused by cancer, cancer patients experience worries about coronavirus as important challenges in their lives. These results indicate the effect of the COVID-19 outbreak on cancer patients and the continuation of treatment. Cancer patients' medical treatments and complication management must be proportional to their conditions and the epidemic pattern of the region. ${ }^{45}$ Physicians can also help moderate patients' anxiety, use telemedicine to examine anxiety and fear of relapse, and provide appropriate psychological referrals. ${ }^{46}$ Studies have shown that depression and anxiety are associated with impaired survival in cancer patients ${ }^{47,48}$ and early psychological interventions in cancer patients can lead to longer survival. ${ }^{49}$

The results of the present study did not show a significant relationship between CDAS and mindfulness. Contrary to the results of the present study, Fong and $\mathrm{Ho}^{50}$ showed positive effects of mindfulness on mental and psychological quality of the colorectal cancer patients by controlling symptoms and emotional distress such as anxiety. Lam et al'.s ${ }^{51}$ study showed that low mindfulness was associated with higher levels of symptoms of depression and anxiety, and that mindfulness might protect against psychological distress in cancer patients. This difference may be due to the different questionnaire used by Fong and $\mathrm{Ho}^{50}$ (Hospital Anxiety and Depression Scale), which does not specifically address coronavirus anxiety and refers to hospital anxiety. The aforementioned study was also conducted before the onset of corona outbreak when patients were not involved with problems associated with corona. The corona outbreak may increase the levels of fear and anxiety in cancer patients and diminish the impact of mindfulness. These results highlight the profound impact of coronavirus on the anxiety of cancer patients, which can lead to future problems for them. Numerous studies have shown that mindfulness is associated with reduced levels of anxiety and depression. ${ }^{52-55}$ Belen $^{56}$ found that fear of COVID-19 and anxiety were inversely related to mindfulness and that more mindfulness might protect individuals against the negative effects of fear of coronavirus, anxiety and depression, and improve mental health during the COVID-19 epidemic. Mindfulness refers to the awareness and acceptance of the presence. Although it may cause people to experience less negative symptoms and anxiety during the COVID-19 outbreak, given the specific circumstances of cancer patients and many problems associated with the disease, the mindfulness may not affect the anxiety of cancer patients alone. The use of two different questionnaires, sampling at different times in different populations with different prevalence of COVID-19 may be the reasons for different results in the present study and the Belen's study. ${ }^{56}$ However, researchers have proposed mindfulness as a useful way to adapt to ongoing change and to cope with anxiety and depression during the coronavirus outbreak. ${ }^{57}$ Further research is required because of the lack of research on the relationship between coronavirus anxiety and mindfulness and the profound effects of the coronavirus on cancer patients.

The present study did not show a significant relationship between CDAS and spiritual health. However, Abou Chaar et al. ${ }^{58}$ showed that spirituality could reduce the levels of anxiety and depression in cancer patients. In addition, Rabow and Knish ${ }^{59}$ showed that spiritual well-being reduced anxiety and depression. Musarezaie ${ }^{60}$ also showed a statistically significant relationship between spiritual health and anxiety scores in cancer patients, i.e. patients with a tendency to spiritual life had lower anxiety. Spiritual beliefs are often considered as a source for dealing with illness and making decisions on treatment of the patients with chronic illness. Chen et al. ${ }^{61}$ showed that spiritual well-being was associated with reduced anxiety and depression. Health care providers need to pay more attention to spiritual care and help cancer patients with spiritual psychological counseling.

However, a relationship was observed between religious beliefs and adverse health outcomes in some patients. For example, the negative effects of religion (i.e., feelings of punishment and spiritual dissatisfaction) are associated with an increased risk of anxiety, depression, and poor quality of life. ${ }^{62,63}$ In the present study, cancer patients had good spiritual health (27.7\%: high and $71.7 \%$ : moderate). In other words, the high spiritual health of the study population may not determine the relationship between spiritual health and coronavirus anxiety. It has also been reported that attending religious ceremonies and praying every day or more than once a day, patients gain more strength and peace of mind to cope with daily stressors. ${ }^{64} \mathrm{CO}$ VID-19 disease crisis, reduced communication and quarantine can also be reasons that have affected cancer patients. The farreaching effects of the corona outbreak can also affect the re- 
ligious aspects and beliefs of cancer patients. Since the present study is the first one, which investigates the relationship between coronavirus anxiety and spiritual health, further research is needed to confirm these results.

\section{Study limitations}

Our study has some limitations in that should be addressed in future. The self-report results of the patients may not always reflect a valid level of psychological impact and anxiety of the cancer patients. The present study is a cross-sectional one that does not deal with the cause and effect relationship and future research should be in the form of longer longitudinal designs or interventional study. The specific condition of cancer patients and the long course of treatment can affect the variables of mindfulness, spiritual health and anxiety caused by coronavirus in these patients, so the results should be generalized with caution. To our knowledge, this is the first study, which examines the relationship between spiritual health and anxiety caused by coronavirus in cancer patients that needs to be investigated in future studies. These results were obtained from Iranian patients, which may not indicate the anxiety status of cancer patients outside Iran due to different cultures and social systems.

\section{Clinical implications}

The results of this study showed that the prevalence of COVID-19 caused anxiety and problems in cancer patients to continue their treatment. Therefore, cancer patients' conditions and the pattern of COVID-19 epidemic of the region must be considered to allocate proper medical treatments and manage the patients. Although in the present study, mindfulness and spiritual health were not associated with anxiety caused by coronavirus in cancer patients, these results should be considered in future studies and effective methods are required to reduce cancer patients' anxiety and prevent the long and lasting consequences.

In conclusion, the results of this study showed that cancer patients had high levels of mental and physical anxiety and their worries about the prevalence of coronavirus caused challenges in their lives. Mindfulness and spiritual health were not associated with anxiety caused by coronavirus in cancer patients. The results of this study can help identify levels of coronavirus anxiety and possible related factors for the development and recognition of future interventions, clinical guidance and planning in crises such as coronavirus.

\section{Acknowledgments}

We would like to thank all patients for their cooperation. The approved research project code was 99000134 .

The code of ethics (IR.KMU.REC.1399.182) was received from the Ethics Committee of Kerman University of Medical Sciences.

\section{Conflicts of Interest}

The authors have no potential conflicts of interest to disclose.

\section{Author Contributions}

Conceptualization: Mahlagha Dehghan. Data curation: Mahlagha Dehghan, Zakieh Namjoo, Ahmad Zarei, Hanieh Tajedini, Amir Bahrami. Formal analysis: Mahlagha Dehghan. Investigation: Mahlagha Dehghan, Zakieh Namjoo, Ahmad Zarei, Hanieh Tajedini, Amir Bahrami. Methodology: Mahlagha Dehghan. Project administration: Mahlagha Dehghan. Supervision: Mahlagha Dehghan. Validation: Mahlagha Dehghan. Visualization: Mahlagha Dehghan. Writing_original draft: Mohammad Ali Zakeri. Writing—review \& editing: Mahlagha Dehghan, Mohammad Ali Zakeri.

\section{ORCID iDs}

Mahlagha Dehghan

Zakieh Namjoo

Ahmad Zarei

Hanieh Tajedini

Amir Bahrami

Mohammad Ali Zakeri
https://orcid.org/0000-0002-4205-829X https://orcid.org/0000-0002-7345-4332 https://orcid.org/0000-0001-5335-3887 https://orcid.org/0000-0003-1964-7237 https://orcid.org/0000-0002-1908-3067 https://orcid.org/0000-0003-1500-391X

\section{REFERENCES}

1. Ornell F, Schuch JB, Sordi AO, Kessler FHP. "Pandemic fear" and COVID-19: mental health burden and strategies. Braz J Psychiatry 2020; 42:232-235.

2. Sun P, Qie S, Liu Z, Ren J, Xi JJ. Clinical characteristics of 50466 patients with 2019-nCoV infection. medRxiv 2020.

3. Liang W, Guan W, Chen R, Wang W, Li J, Xu K, et al. Cancer patients in SARS-CoV-2 infection: a nationwide analysis in China. Lancet Oncol 2020;21:335-357.

4. Siegel RL, Miller KD, Jemal A. Cancer statistics, 2019. CA Cancer J Clin 2019;69:7-34

5. Miller KD, Nogueira L, Mariotto AB, Rowland JH, Yabroff KR, Alfano CM, et al. Cancer treatment and survivorship statistics, 2019. CA Cancer J Clin 2019;69:363-385.

6. Sica A, Massarotti M. Myeloid suppressor cells in cancer and autoimmunity. J Autoimmun 2017;85:117-125.

7. Longbottom ER, Torrance HD, Owen HC, Fragkou PC, Hinds CJ, Pearse RM, et al. Features of postoperative immune suppression are reversible with interferon gamma and independent of interleukin-6 pathways. Ann Surg 2016;264:370-377.

8. Fillmore NR, La J, Szalat RE, Tuck DP, Nguyen V, Yildirim C, et al. Prevalence and outcome of COVID-19 infection in cancer patients: a national Veterans Affairs study. J Natl Cancer Inst 2020; djaa159.

9. Guo Y, Shen M, Zhang X, Xiao Y, Zhao S, Yin M, et al. Unemployment and health-related quality of life in melanoma patients during the COVID-19 pandemic: a web-based cross-sectional study. Front Public Health 2021;9:630620

10. Zakeri MA, Dehghan M. The impact of the COVID-19 disease on the referral and admission of the non-COVID-19 patients. Int J Health Plann Manage 2021;36:209-211.

11. Shinan-Altman S, Levkovich I, Tavori G. Healthcare utilization among breast cancer patients during the COVID-19 outbreak. Palliat Support Care 2020;18:385-391.

12. Hossini Rafsanjanipoor SM, Zakeri MA, Dehghan M, Kahnooji M, Sanji Rafsanjani M, Ahmadinia H, et al. Iranian psychosocial status and its determinant factors during the prevalence of COVID-19 disease. Psychol Health Med 2021;1-12.

13. Zakeri MA, Dehghan M, Ghaedi Heidari F, Pakdaman H. Mental Health Outcomes among Health Care Workers during the COVID-19 outbreak in Iran. Ment Health Rev J 2021 [Online ahead of print]

14. Nyatanga B, de Vocht H. Towards a definition of death anxiety. Int J Palliat Nurs 2006;12:410-413. 
15. Kang YS, Choi SY, Ryu E. The effectiveness of a stress coping program based on mindfulness meditation on the stress, anxiety, and depression experienced by nursing students in Korea. Nurse Educ Today 2009;29: 538-543.

16. Germer CK, Siegel RD, Fulton PR. Mindfulness and Psychotherapy. (2nd Ed.). New York City: Guilford Press; 2013.

17. Walsh JJ, Balint MG, Smolira DR, Fredericksen LK, Madsen S. Predicting individual differences in mindfulness: the role of trait anxiety, attachment anxiety and attentional control. Pers Individ Dif 2009;46:94-99.

18. Reich RR, Lengacher CA, Klein TW, Newton C, Shivers S, Ramesar S, et al. A randomized controlled trial of the effects of Mindfulness-Based Stress Reduction (MBSR [BC]) on levels of inflammatory biomarkers among recovering breast cancer survivors. Biol Res Nurs 2017;19:456464.

19. Liu T, Zhang W, Xiao S, Xu L, Wen Q, Bai L, et al. Mindfulness-based stress reduction in patients with differentiated thyroid cancer receiving radioactive iodine therapy: a randomized controlled trial. Cancer Manag Res 2019;11:467-474.

20. Lengacher CA, Kip KE, Post-White J, Fitzgerald S, Newton C, Barta M, et al. Lymphocyte recovery after breast cancer treatment and mindfulness-based stress reduction (MBSR) therapy. Biol Res Nurs 2013;15:3747.

21. Piet J, Würtzen H, Zachariae R. The effect of mindfulness-based therapy on symptoms of anxiety and depression in adult cancer patients and survivors: a systematic review and meta-analysis. J Consult Clin Psychol 2012;80:1007-1020.

22. Rasmussen MK, Pidgeon AM. The direct and indirect benefits of dispositional mindfulness on self-esteem and social anxiety. Anxiety Stress Coping 2011;24:227-233.

23. Dehghan M, Jazinizade M, Malakoutikhah A, Madadimahani A, Iranmanesh $\mathrm{MH}$, Oghabian S, et al. Stress and quality of life of patients with cancer: the mediating role of mindfulness. J Oncol 2020;2020:3289521.

24. Mehdi Pour H, Kord B. The relationship of mindfulness and perceived self-efficacy with subjective well-being in hospitalized patients with cancer in Tabriz, Iran. Ir J Nurs Res 2018;13:11-17.

25. Tate KJ, Newbury-Birch D, McGeechan GJ. A systematic review of qualitative evidence of cancer patients' attitudes to mindfulness. Eur J Cancer Care (Engl) 2018;27:e12783.

26. Hsieh CC, Yu CJ, Chen HJ, Chen YW, Chang NT, Hsiao FH. Dispositional mindfulness, self-compassion, and compassion from others as moderators between stress and depression in caregivers of patients with lung cancer. Psychooncology 2019;28:1498-1505.

27. Zhong M, Zhang Q, Bao J, Xu W. Relationships between meaning in life, dispositional mindfulness, perceived stress, and psychological symptoms among Chinese patients with gastrointestinal cancer. J Nerv Ment Dis 2019;207:34-37.

28. Shah R, Kulhara P, Grover S, Kumar S, Malhotra R, Tyagi S. Relationship between spirituality/religiousness and coping in patients with residual schizophrenia. Qual Life Res 2011;20:1053-1060.

29. Moradi-Joo M, Babazadeh T, Honarvar Z, Mohabat-Bahar S, RahmatiNajarkolaei F, Haghighi M. The relationship between spiritual health and public health aspects among patients with breast cancer (Persian). J Pizhūhish dar dīn va salāmat 2017;3:80-91.

30. Sadat hoseini AS, Razaghi N, Khosro Panah AH, Dehghan Nayeri N. A concept analysis of spiritual health. J Relig Health 2019;58:1025-1046.

31. Zhu Z, Xu S, Wang H, Liu Z, Wu J, Li G, et al. COVID-19 in Wuhan: immediate psychological impact on 5062 Health Workers. medRxiv 2020.

32. Duan L, Zhu G. Psychological interventions for people affected by the COVID-19 epidemic. Lancet Psychiatry 2020;7:300-302.

33. Chen Q, Liang M, Li Y, Guo J, Fei D, Wang L, et al. Mental health care for medical staff in China during the COVID-19 outbreak. Lancet Psychiatry 2020;7:e15-e16.

34. Alipour A, Ghadami A, Alipour Z, Abdollahzadeh H. Preliminary validation of the Corona Disease Anxiety Scale (CDAS) in the Iranian sample. [persian]. Quart J Health Psychol 2020;8:163-175.

35. Walach H, Buchheld N, Buttenmüller V, Kleinknecht N, Schmidt S. Measuring mindfulness-the Freiburg Mindfulness Inventory (FMI). Pers Individ Dif 2006;40:1543-1555.

36. Buchheld N, Grossman P, Walach H. Measuring Mindfulness in insight meditation and Meditation-Based Psychotherapy: the development of the Freiburg Mindfulness Questionnaire (FMI). J Medit Medit Res 2001;1:11-35.

37. Kohls N, Sauer S, Walach H. Facets of mindfulness - Results of an online study investigating the Freiburg mindfulness inventory. Pers Individ Dif 2009;46:224-230.

38. Ghasemi Jobaneh R, Arab Zadeh M, Jalili Nikoo S, Mohammad Alipoor Z, Mohsenzadeh FJM. Survey the validity and reliability of the Persian version of short form of Freiburg Mindfulness Inventory. JRUMS 2015;14:137-150.

39. Rahimi N, Nouhi E, Nakhaee N. Spiritual health among nursing and midwifery students at kerman university of medical sciences. J Hayat 2014;19:74-81.

40. Polizzi C, Lynn SJ, Perry A. Stress and coping in the time of COVID-19: Pathways to resilience and recovery. Clin Neuropsychiatry 2020;17:5962.

41. Shankar A, Saini D, Roy S, Mosavi Jarrahi A, Chakraborty A, Bharti SJ, et al. Cancer care delivery challenges amidst coronavirus disease-19 (COVID-19) outbreak: specific precautions for cancer patients and cancer care providers to prevent spread. Asian Pac J Cancer Prev 2020;21: 569-573.

42. Moujaess E, Kourie HR, Ghosn M. Cancer patients and research during COVID-19 pandemic: a systematic review of current evidence. Crit Rev Oncol Hematol 2020;150:102972.

43. Hoda W, Bharati SJ, Kumar A, Choudhary P, Shankar A. Socio-cultural and economic impact of corona virus on cancer patients, caregivers and survivors. Asian Pac J Cancer Prev 2020;5:171-173.

44. Büntzel J, Klein M, Keinki C, Walter S, Büntzel J, Hübner J. Oncology services in corona times: a flash interview among German cancer patients and their physicians. J Cancer Res Clin Oncol 2020;146:27132715.

45. Zhao Z, Bai H, Duan J, Wang J. Recommendations of individualized medical treatment and common adverse events management for lung cancer patients during the outbreak of COVID-19 epidemic. Thorac Cancer 2020;11:1752-1757.

46. Butow P, Sharpe L, Thewes B, Turner J, Gilchrist J, Beith J. Fear of cancer recurrence: a practical guide for clinicians. Oncology (Williston Park) 2018;32:32-38.

47. Pitman A, Suleman S, Hyde N, Hodgkiss A. Depression and anxiety in patients with cancer. BMJ 2018;361:k1514

48. Kim SJ, Kang D, Kim IR, Yoon SE, Kim WS, Butow PN, et al. Impact of fear of cancer recurrence on survival among lymphoma patients. Psychooncology 2020;29:364-372.

49. Temel JS, Greer JA, Muzikansky A, Gallagher ER, Admane S, Jackson VA, et al. Early palliative care for patients with metastatic non-smallcell lung cancer. New Engl J Med 2010;363:733-742.

50. Fong TC, Ho RT. Mindfulness facets predict quality of life and sleep disturbance via physical and emotional distresses in Chinese cancer patients: a moderated mediation analysis. Psychooncology 2020;29: 894-901.

51. Lam KF, Lim HA, Kua EH, Griva K, Mahendran R. Mindfulness and cancer patients' emotional states: a latent profile analysis among newly diagnosed cancer patients. Mindfulness 2018;9:521-533.

52. Montero-Marin J, Van Gordon W, Shonin E, Navarro-Gil M, Gasión V, López-del-Hoyo Y, et al. Attachment-based compassion therapy for ameliorating fibromyalgia: mediating role of mindfulness and selfcompassion. Mindfulness 2020;11:816-828.

53. Li G, Jiang Z, Han X, Shang X, Tian W, Kang X, et al. A moderated mediation model of perceived stress, negative emotions and mindfulness on fertility quality of life in women with recurrent pregnancy loss. 
Qual Life Res 2020;29:1775-1787.

54. MacDonald HZ, Olsen A. The role of attentional control in the relationship between mindfulness and anxiety. Psychol Rep 2020;123:759-780.

55. Makadi E, Koszycki D. Exploring connections between self-compassion, mindfulness, and social anxiety. Mindfulness 2020;11:480-492.

56. Belen H. Fear of COVID-19 and mental health: the role of mindfulness in during time of crisis. Res Square 2020 Preprint.

57. Behan C. The benefits of Meditation and Mindfulness practices during times of crisis such as COVID-19. Ir J Psychol Med 2020;37:256-258.

58. Chaar EA, Hallit S, Hajj A, Aaraj R, Kattan J, Jabbour H, et al. Evaluating the impact of spirituality on the quality of life, anxiety, and depression among patients with cancer: an observational transversal study. Support Care Cancer 2018;26:2581-2590.

59. Rabow MW, Knish SJ. Spiritual well-being among outpatients with cancer receiving concurrent oncologic and palliative care. Support Care Cancer 2015;23:919-923.

60. Musarezaie A. The relationship between spiritual wellbeing with stress, anxiety, and some demographic variables in women with breast cancer referring to the specialized cancer treatment center in Isfahan, Iran. [persian]. Health Syst Res 2012;8:104-113.

61. Chen J, You H, Liu Y, Kong Q, Lei A, Guo X. Association between spiritual well-being, quality of life, anxiety and depression in patients with gynaecological cancer in China. Medicine (Baltimore) 2021;100:e24264.

62. McConnell KM, Pargament KI, Ellison CG, Flannelly KJ. Examining the links between spiritual struggles and symptoms of psychopathology in a national sample. J Clin Psychol 2006;62:1469-1484.

63. Whitford HS, Olver IN, Peterson MJ. Spirituality as a core domain in the assessment of quality of life in oncology. Psychooncology 2008;17: 1121-1128.

64. Munoz AR, Salsman JM, Stein KD, Cella D. Reference values of the Functional Assessment of Chronic Illness Therapy-Spiritual Well-Being: a report from the American Cancer Society's studies of cancer survivors. Cancer 2015;121:1838-1844. 